\title{
Investigation into Mechanical Properties and Sliding Wear Behavior of Friction Stir Processed Surface Composite Material
}

\author{
Anbuchezhian Nattappan, ${ }^{1}$ G. Suganya Priyadharshini, ${ }^{2}$ T. Satish Kumar, ${ }^{3}$ \\ T. Velmurugan, ${ }^{4}$ M. Makeshkumar, ${ }^{5}$ and Haiter Lenin Allasi $\mathbb{i D}^{6}$ \\ ${ }^{1}$ R.M.D Engineering College, Kavaraipettai, Tiruvallur, Tamil Nadu, India \\ ${ }^{2}$ Department of Mechanical Engineering, Coimbatore Institute of Technology, Coimbatore, Tamil Nadu, India \\ ${ }^{3}$ Department of Mechanical Engineering, Amrita School of Engineering, Amrita Vishwa Vidyapeetham, Coimbatore, \\ Tamil Nadu, India \\ ${ }^{4}$ Department of Mechanical Engineering, Sri Ramakrishna Engineering College, Coimbatore, Tamil Nadu, India \\ ${ }^{5}$ Department of Mechanical Engineering, KPR Institute of Engineering and Technology, Coimbatore, Tamil Nadu, India \\ ${ }^{6}$ Department of Mechanical Engineering, Wollo University Kombolcha Institute of Technology, P.O. Box 208, Kombolcha, \\ Ethiopia
}

Correspondence should be addressed to Haiter Lenin Allasi; drahlenin@kiot.edu.et

Received 18 August 2021; Accepted 30 October 2021; Published 19 November 2021

Academic Editor: JT Winowlin Jappes

Copyright (C) 2021 Anbuchezhian Nattappan et al. This is an open access article distributed under the Creative Commons Attribution License, which permits unrestricted use, distribution, and reproduction in any medium, provided the original work is properly cited.

\begin{abstract}
One of the different and pioneering solid-state techniques, friction stir processing (FSP), is employed for the production of surface composites. In this research, the matrix selected was copper-nickel $(\mathrm{CuNi})$ with hard boron carbide particle as reinforcement. The objective of the current research work is to produce reinforced 90/10 copper-nickel surface composites reinforced with $\mathrm{B}_{4} \mathrm{C}$ fabricated via FSP. The influence of tool rotational speed on macrostructure, microstructure, grain size analysis, microhardness, and wear studies of friction stir processed (FSPed) $\mathrm{CuNi} / \mathrm{B}_{4} \mathrm{C}$ surface composites was assessed. For high rotational speed $(1400 \mathrm{rpm})$ of stir tool, the modified surface area found is a maximum of $44.4 \mathrm{~mm}^{2}$ with uniform dispersion of hard particle reinforcement. The presence of hard particle in the surface area is revealed through the electron imaging and the spectroscopic results. Spectra mapping shows the uniform distribution of hard particle over the FSPed area, and the evidence is obtained with $\mathrm{XRD}$ analysis. From the experimentation, it is interesting to report that the reinforcements have decreased the surface hardness for an increased rotational speed of stir tool. The hardness recorded for minimum rotational speed is $223 \mathrm{HV}$ which has gradually decreased to $178 \mathrm{HV}$ for $1300 \mathrm{rpm}$. It has directly influenced the wear rate of modified FSPed, as hardness is directly proportional to wear behavior. The worn surface and fractured morphology of the $\mathrm{CuNi} / \mathrm{B}_{4} \mathrm{C}$ surface composites were also studied using Field Emission Scanning Electron Microscope (FESEM).
\end{abstract}

\section{Introduction}

The evolution of modern material science and techniques of material synthesis has developed the production of composite materials with enhanced performance for use in aerospace and other demanding industrial applications. Composite materials are one of the essential and versatile engineering materials. The development in the field of material science and technology has made the production of advanced composite materials possible. Composite materials possess a unique combination of properties such as high strength, high toughness, lightweight, low cost, good damping capacity, wear resistance, corrosion resistance, hardness, conductivity, creep strength, fatigue strength, negative thermal expansion coefficient, and unusual combinations of electrical and magnetic properties depending on their alloying elements and processing techniques.

Cupronickel $(\mathrm{CuNi})$ alloy is extensively used for high temperature and corrosion resistance applications. The 
typical applications are in marine and petrochemical sectors including components for ship and boat hulls, desalination plants, and heat exchangers, as well as multicore cabled tubes for hydraulic and pneumatic lines. It has been selected for the superior properties of the materials [1]. However, this alloy is extremely susceptible to mechanical failure before its predicted lifetime [2], due to harsh and demanding tribological conditions. To meet such demanding mechanical and surface property requirements, this alloy can be subjected to surface processing techniques.

Friction stir processing (FSP) has emerged as a distinctive and pioneering solid-state technique to produce surface composites. FSP was developed based on the principles of Friction Stir Welding (FSW) [3-5]. FSP is a green and energy efficient technology because, during FS process, heat is produced from friction and plastic deformation without any noise or gaseous emission, as in conventional welding processes. FS processing results in a defect-free recrystallized zone with fine-grained microstructure. FS processing produces significant changes in regions close to the processed zone, without affecting the base metal [6]. Due to the frictional force and heat produced, the substrate metal is extruded and forged behind the tool forming a surface coating over the surface of the substrate metal. The type of tool material selected, its size, and tool profile play a key role in determining the quality of the weld. Mahmoud et al. [7] employed FSP to disperse SiC particles uniformly onto the surface of A1050-H24 aluminium alloy. Microstructural characterization of the developed surface composites indicated that $\mathrm{SiC}$ particles were dispersed uniformly onto the aluminium surface with the aid of square profile tools when compared to other profiles. Outstanding hardness, high melting point, high resistance to chemical agents, and high neutron absorption pave the way to the boron carbide $\left(\mathrm{B}_{4} \mathrm{C}\right)$ being acceptable in the fields of nuclear applications, lightweight armors, and fast breeders [8]. Nuclear industries use boron carbide extensively due to its high neutron absorption [9].

From the comprehensive literature survey, it was found that difficulties involved in liquid phase technique have led to the evolution of solid-state processing approach. Most of the researchers' studies on FSP are related to aluminium alloy, copper, stainless steel, and magnesium alloy compacted with and without carbide, nitrides, and oxide particles. It was found that there is no work related to fabrication and characterization of cupronickel $(90 \% \mathrm{Cu}$ and $10 \% \mathrm{Ni})(\mathrm{CuNi})$ alloy based surface composite processed through FSP. The proposed research explores the microstructural properties, mechanical properties, and dry sliding wear behavior of $\mathrm{CuNi}$ surface composite reinforced with $\mathrm{B}_{4} \mathrm{C}$ processed using green and energy efficient FSP technique.

\section{Experimental Procedure}

Commercially available $\mathrm{CuNi}$ sheet of size $100 \mathrm{~mm} \times 50 \mathrm{~mm} \times 6 \mathrm{~mm}$ was selected as matrix material in the current study. From the results of optical emission spectroscopy analysis, nickel (11.43 wt\%) is the major alloying element together with $0.03 \mathrm{wt} \% \mathrm{Zn}, 0.79 \mathrm{wt} \% \mathrm{Mn}$, and $1.20 \mathrm{wt} \% \mathrm{Fe}$, and the rest is copper. As received, $\mathrm{CuNi}$ matrix and the reinforcement $\left(\mathrm{B}_{4} \mathrm{C}\right)$ are shown in Figure 1 . The square groove of $100 \mathrm{~mm}$ length, $2.5 \mathrm{~mm}$ depth, and $0.7 \mathrm{~mm}$ width was made at the center of each plate employing wire $\mathrm{EDM}$ for adding the $\mathrm{B}_{4} \mathrm{C}$ ceramic particles. Two-stage friction stir processing of the plates was carried over employing primitive made FSW. Initially, tungsten carbide pinless tool helps to close the groove so as to avoid $\mathrm{B}_{4} \mathrm{C}$ ceramic particles spilling out during FSP. In the subsequent stage, a FSP tool made of the same WC material, with shoulder diameter of $25 \mathrm{~mm}$ and taper pin profile with pin tip diameter of $3 \mathrm{~mm}$ and pin root diameter of $5 \mathrm{~mm}$ to a span of $3 \mathrm{~mm}$, was used. The FSP procedure to produce surface composite is schematically shown in Figure 2.

The FSPed specimen of size $10 \mathrm{~mm} \times 50 \mathrm{~mm} \times 6 \mathrm{~mm}$ was prepared from FSP plates by sectioning. The FSPed samples were polished and etched with several emery papers. The two types of etchants used in the friction stir zone are (i) Kalling's reagent (an optimized composition of $\mathrm{CuCl}, \mathrm{HCl}$, and ethanol, with the soaking time being 30 seconds) and (ii) a combination of $\mathrm{FeCl}_{3}$, ethanol, and $\mathrm{HCl}$ which was exposed for 40 seconds. Macrostructure analysis was exposed using digital image scanner, and an image analyzer was used to measure the surface area of the composite. The microstructures of the FSPed samples were studied using optical microscope and FESEM. The microhardness of the developed surface composites was studied at different areas like thermomechanically affected region, heat affected region, and stir region. The parameters used for microhardness tests are load of $300 \mathrm{~g}$ and dwell time of 20 seconds. Dry sliding wear test was performed with ASTM G99-04 standard to study the friction, and wear of the developed surface composites under the condition of $30 \mathrm{~N}$ was applied. The other parameters considered for the dry sliding wear tests are sliding velocity and sliding distance of $1.5 \mathrm{~m} / \mathrm{s}$ and $2500 \mathrm{~m}$.

\section{Results and Discussion}

The rotating tool consists of a pin of required diameter and length, and a concentric outsized diameter shoulder. Both the pin and shoulder control the penetration depth along the plate. When the pin tool contacts the matrix metal, the shoulder of the tool decides the depth of the pin. The contact between the shoulder and the matrix metal causes a forging force that leads to generation of localized fractional heat to soften the parent material and mixes the hard particles with the help of pin protrusion. During FSP, the tool is rotated at the required speed, and the plate to be processed moves (traverse speed) against the rotating tool to complete a pass in the selected area. While transporting the parent metal from the advancing side to the retreating side, hot working action takes place due to the tool rotation.

To study the influence of stir tool rotational speed on $\mathrm{CuNi} / \mathrm{B}_{4} \mathrm{C}$ surface composite, probable trials were done with several varying speeds. The optimized rotational speed is from $1000 \mathrm{rpm}$ to $1400 \mathrm{rpm}$ (with an increment of $200 \mathrm{rpm}$ ), while fixing the other parameters (traverse speed $=30 \mathrm{~mm} /$ min, groove width $=0.7 \mathrm{~mm}$, axial load $=6 \mathrm{kN}$, carbide 

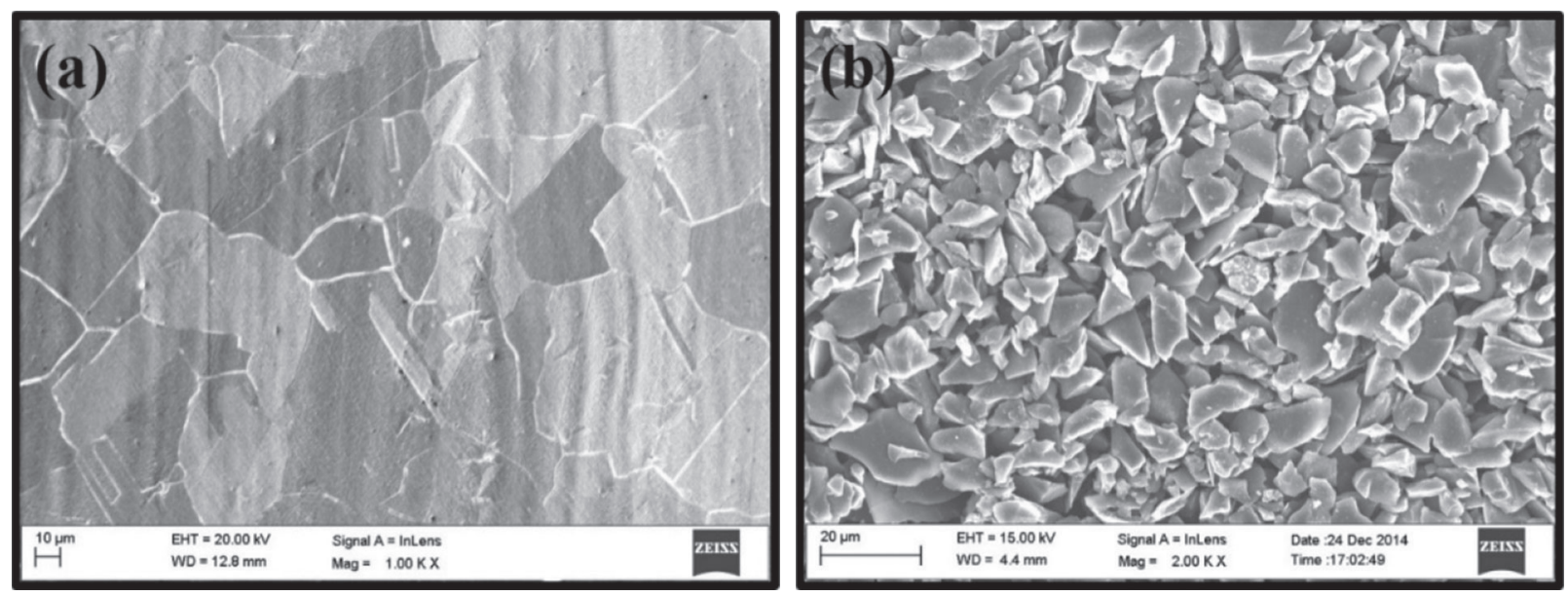

FIgURE 1: FESEM image of (a) CuNi and (b) boron carbide particle.

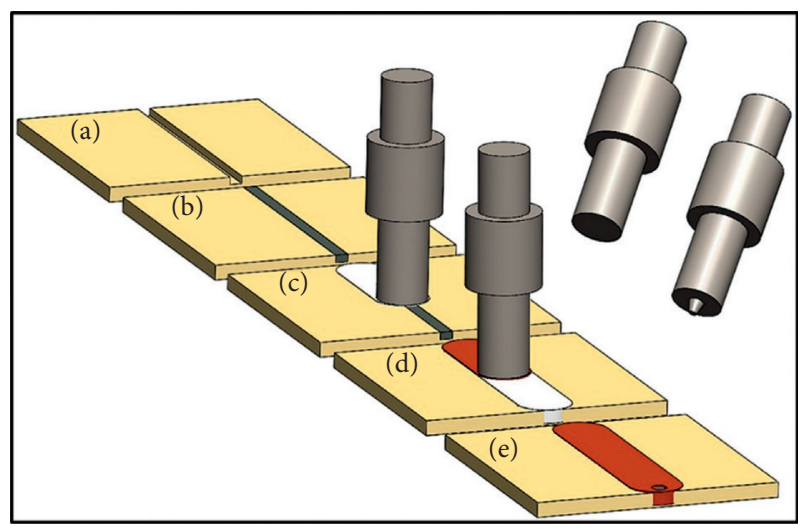

Figure 2: Friction stir processing and different stages: (a) preparation of groove; (b) charging the groove with ceramic particles; (c) processing via tool without pin; (d) processing via tool with pin; (e) processed plate.

particle content $\mathrm{B}_{4} \mathrm{C}$ ). Some of the defects like tool dragging insufficient plastic flow and cracks were also found during trials as shown in Figure 3. The attainment in the FSP is the formation of smooth crown appearance, which is achieved through the above set of parameters.

Based on the stir tool geometry and selected process parameters, the level of quality can be measured. During processing, the bulk material was subjected to severe plastic deformation and hardened due to repeated cycle. Figure 4 shows the level of distribution of heat generated during the process (using FLIR T1K infrared (IR) camera). It indicates that the maximum heat generated at stir zone while processing is approximately $734^{\circ} \mathrm{C}$ and down to a minimum of $166^{\circ} \mathrm{C}$. The phase transformation of $\mathrm{CuNi}$ alloy starts from $1100^{\circ} \mathrm{C}$, and thus the change in surface of the material is a mechanical fusion. It leads to surface hardening and strain hardening through plastic deformation with reference to stir tool plunge area.

3.1. Macrostructure of $\mathrm{CuNi} / \mathrm{B}_{4} \mathrm{C}$ Surface Composites. The variation of the stirred area with reference to various tool rotational speed is shown in Figures 5(a)-5(e). The

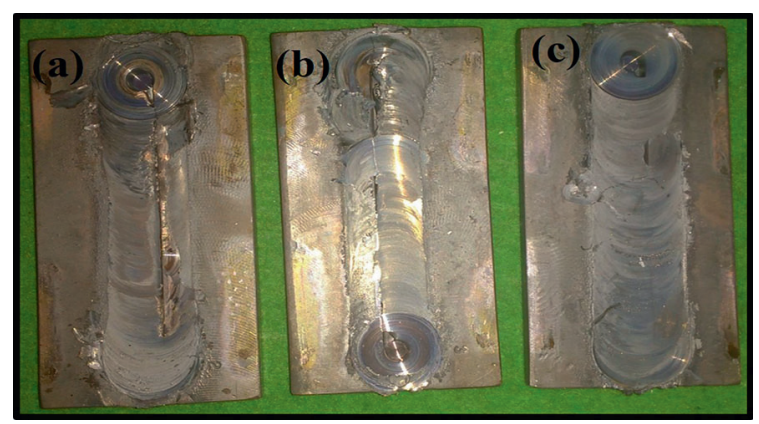

FIGURE 3: Defects that occurred during FSP trial: (a) tunnel defect; (b) tool dragging; (c) crack formation.

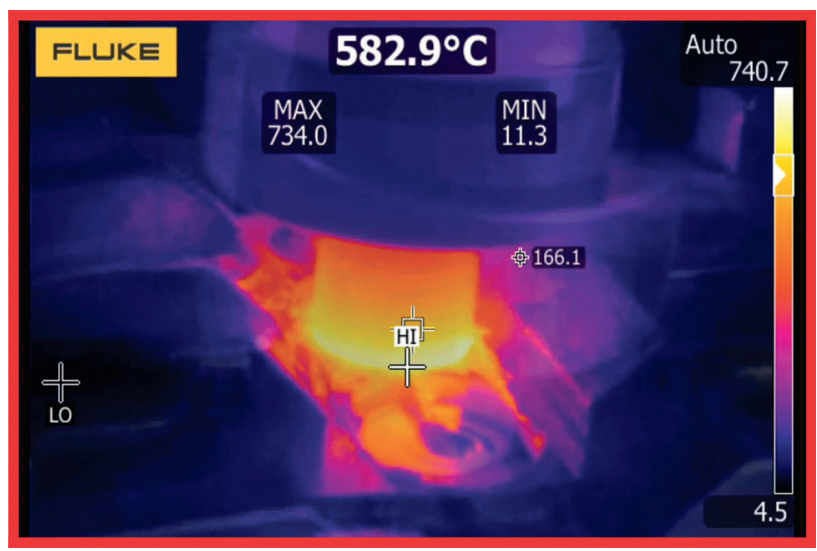

FIgURE 4: Thermal image of the stir zone during surface processing of $\mathrm{CuNi}$ with a reinforcement of $\mathrm{B}_{4} \mathrm{C}$ particle at $1200 \mathrm{rpm}$.

parameters like tool plunge shoulder, groove width, and traverse speed of the process were kept constant. The movement of tool shoulder on the CuNi substrate results in the formation of frictional heat. The total frictional heat produced during the FSP depends upon the tool rotational speed. When the tool rotational speed was low, the formation of surface on advancing side and retreating side was found to be the same as shown in Figure 5(a). When the spindle speed 

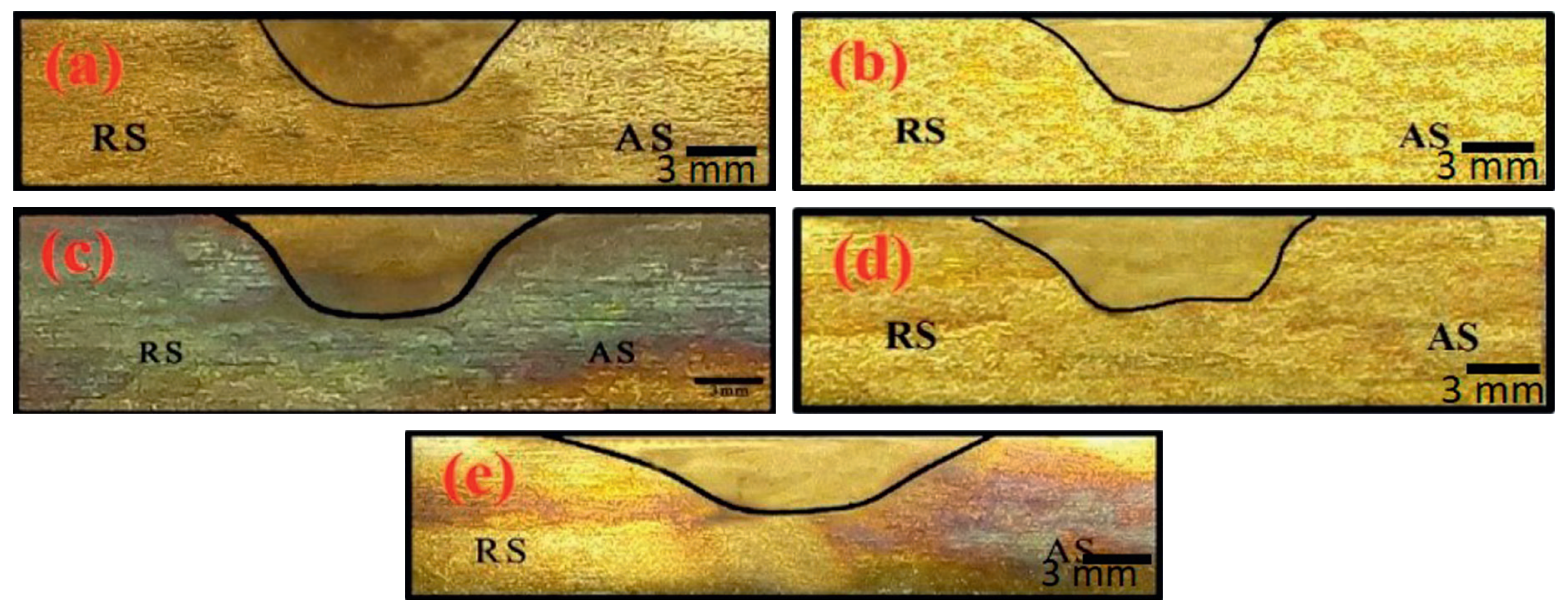

Figure 5: Macro images of CuNi/B ${ }_{4} \mathrm{C}$ surface composite at tool rotational speed of (a) $1000 \mathrm{rpm}$, (b) $1100 \mathrm{rpm}$, (c) $1200 \mathrm{rpm}$, (d) $1300 \mathrm{rpm}$, and (e) $1400 \mathrm{rpm}$.

was increased, there was a maximum drag force on the advancing side which stretched along the retreating side. When the tool rotational speed was raised, the stir surface area started to diverge as shown in Figures 5(b)-5(e). The effect of the whirling speed was pronounced at the top side of the groove, and it was neutral at the bottom of the groove. This can be confirmed by the macro images in Figures 5(b)-5(e). The amount of plasticized material and the flow of the material directed towards the stir area depend upon the movement of the FSP tool and the heat generated during the process. The FSP tool progress and frictional heat generated rely upon the process parameters such as FSP spindle (tool rotational) speed, traverse speed, and groove width. The above-selected process parameters produced defect-free $\mathrm{CuNi}$ reinforced $\mathrm{B}_{4} \mathrm{C}$ surface composite.

The frictional stir area produced with respect to various tool rotational speeds at constant traverse speed, groove width $(S=30 \mathrm{~mm} / \mathrm{min}, W=0.7 \mathrm{~mm})$, and $\mathrm{B}_{4} \mathrm{C}$ particles is shown in Figure 6. It can also be concluded that the frictional area was increased when the tool rotation speed was increased. There was an increase in plasticized CuNi at the FSP area as shown in Figures 5(a)-5(e) which is due to the high frictional heat generation resulting from the increase in the tool rotation speed. From the above observations, it can be concluded that there was an increase in FSP area when the tool rotation speed was increased, which matches the results suggested by [10].

3.2. Microstructure Analysis. The optical microscopic studies of different tool rotation speeds were carried out for studying the presence and distribution of carbide particulates in $\mathrm{CuNi}$ matrix as shown in Figures $7(\mathrm{a})-7(\mathrm{e})$. Onion ring-like structure formation is a prominent feature of FSP which is because of the generation of frictional heat produced during the spindle rotation, and the forward motion of tool forces the matrix material around the retreating side of tool. Woo et al. and Chaitanya et al. [11, 12] concluded that the onion ring structure formation is mainly due to proper selection of process parameters during the FSP. During the FSP of $\mathrm{CuNi}$ /

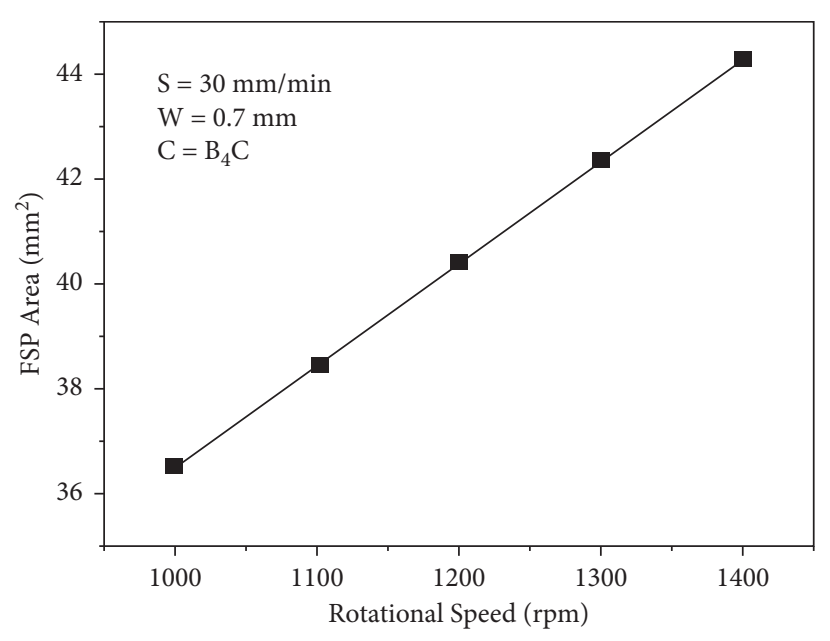

FIgURE 6: Variations in stir area of $\mathrm{CuNi} / \mathrm{B}_{4} \mathrm{C}$ surface composites as a function of tool rotational speed.

$\mathrm{B}_{4} \mathrm{C}$ surface composite, the presence of onion ring-like structure can be clearly seen when the tool rotational speed is $1200 \mathrm{rpm}$ at $30 \mathrm{~mm} / \mathrm{min}$ traverse speed for a groove width of $0.7 \mathrm{~mm}$. During the stir process, carbide particles are uniformly distributed within the base metal in various zones including dynamically plasticized stir zone. The FSPed samples were further investigated by spectroscopic analysis (multipoint and mapping), and the results are shown in Figures 8 and 9. The XRD spectra are shown in Figure 10, which confirms the absence of oxides on the FSPed area. The lack of formation of third phase at the stir zone indicates that FSP is a useful technique for the fabrication of $\mathrm{CuNi} / \mathrm{B}_{4} \mathrm{C}$ surface composite.

3.3. Grain Size Analysis. The grain refinement zone in the FSPed zone was studied using OM and FESEM micrographs, and it is shown in Figures 11 and 12. The presence of particle distribution and the bonding of the bulk material can be visibly seen. The composite layer was bonded well with $\mathrm{CuNi}$ alloy substrate, and no defects like diffusion crack or lack-of- 

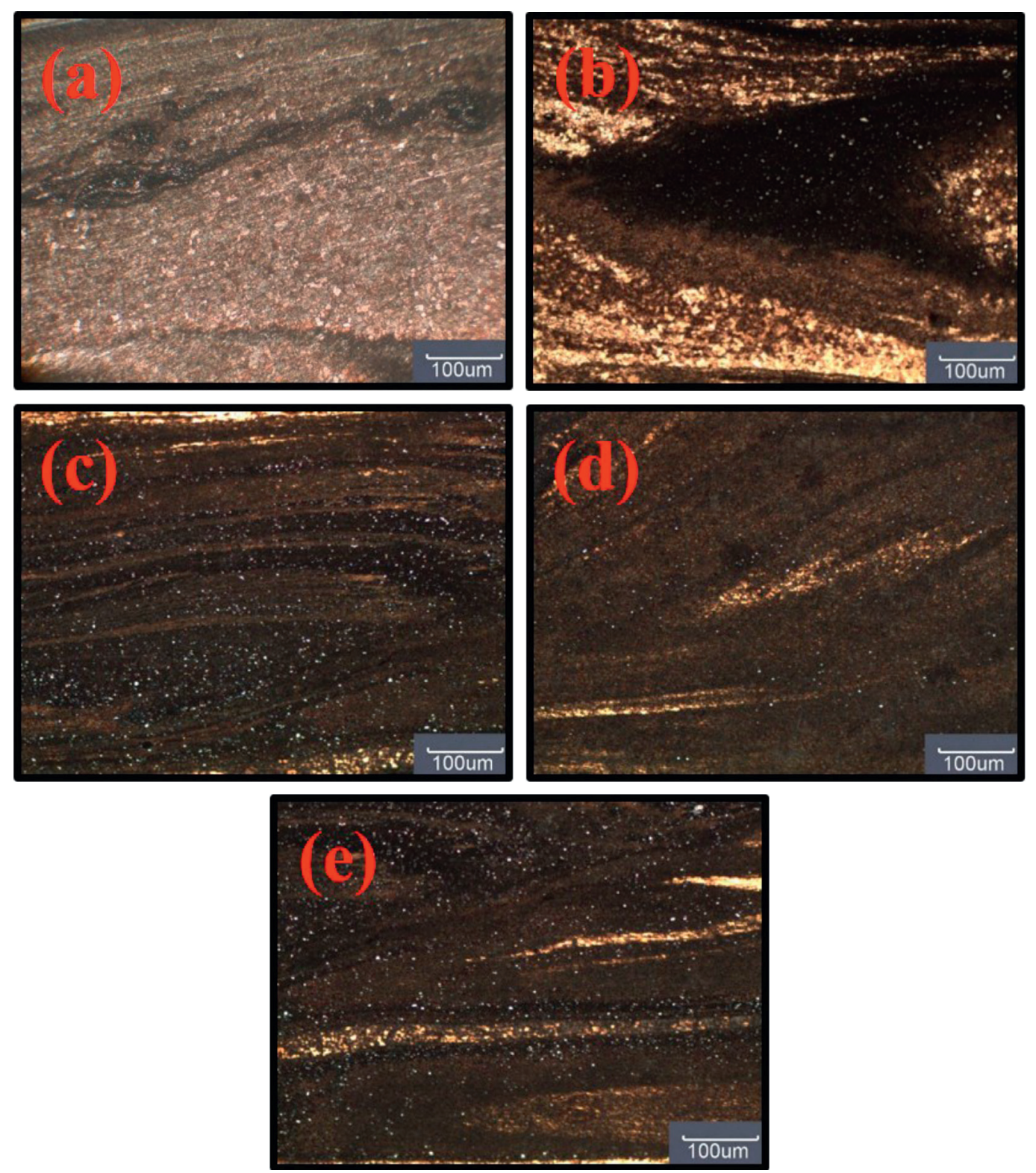

FIGURE 7: Optical microscopic images of stir zone at various tool rotational speeds of (a) $1000 \mathrm{rpm}$, (b) $1100 \mathrm{rpm}$, (c) $1200 \mathrm{rpm}$, (d) $1300 \mathrm{rpm}$, and (e) $1400 \mathrm{rpm}$.

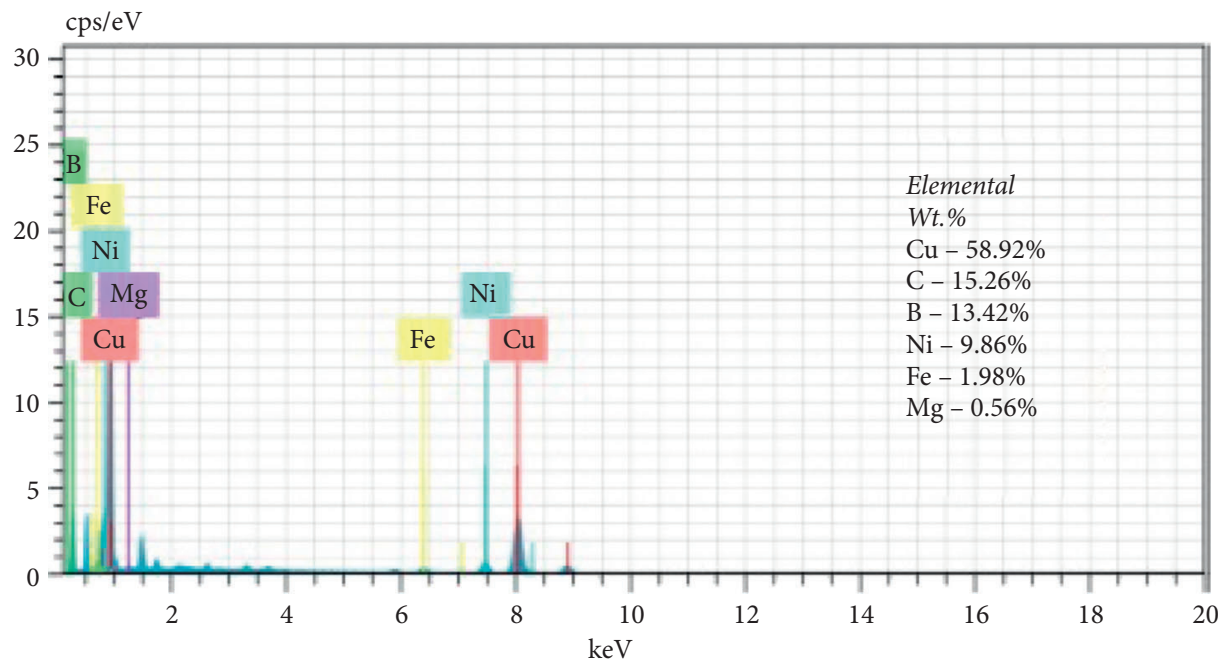

FIGURE 8: EDS (multipoint) analysis of FSP sample indicating reinforcement of $\mathrm{B}_{4} \mathrm{C}$ particle in CuNi alloy. 

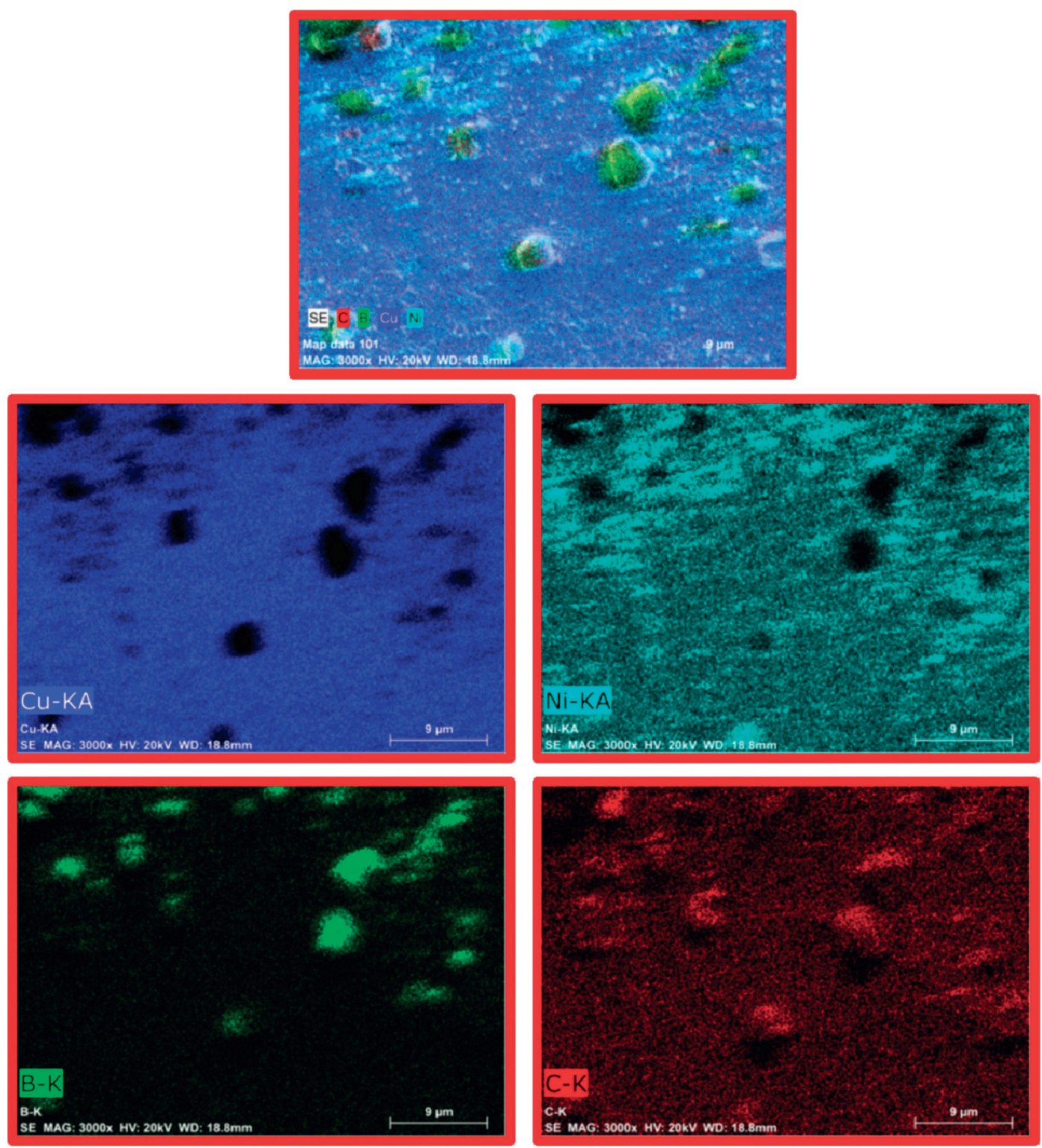

FIgURE 9: Electron image mapping of FSP sample indicating reinforcement of $\mathrm{B}_{4} \mathrm{C}$ particle in CuNi alloy.

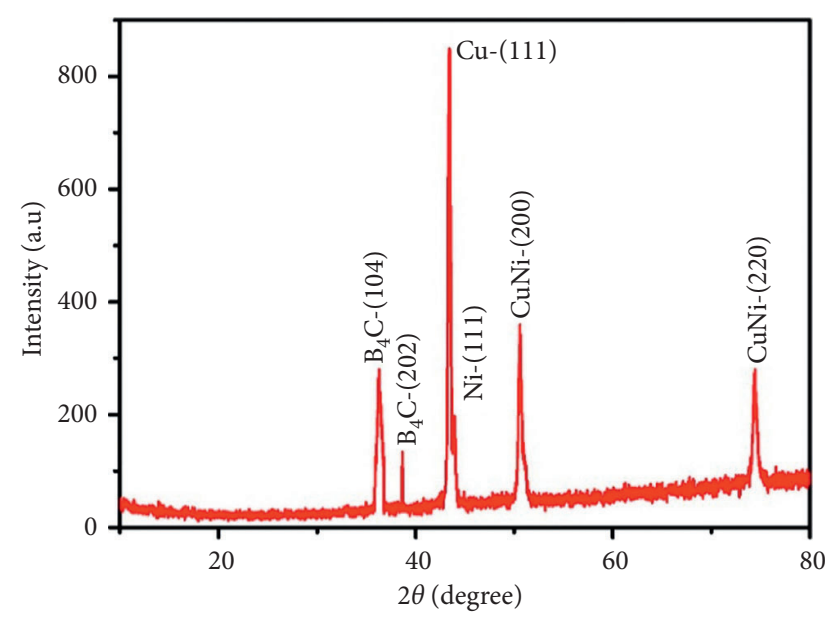

FIGURE 10: XRD analysis of FSP sample indicating the dominating peaks of reinforced carbide particle and base material.

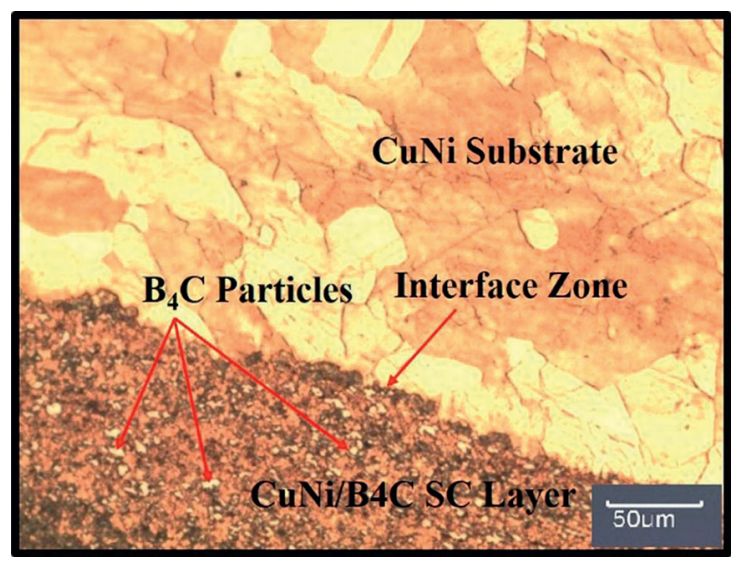

FIGURE 11: Optical micrograph showing interface zone between $\mathrm{CuNi}$ alloy substrate and $\mathrm{CuNi} / \mathrm{B}_{4} \mathrm{C}$ surface composite layer. 


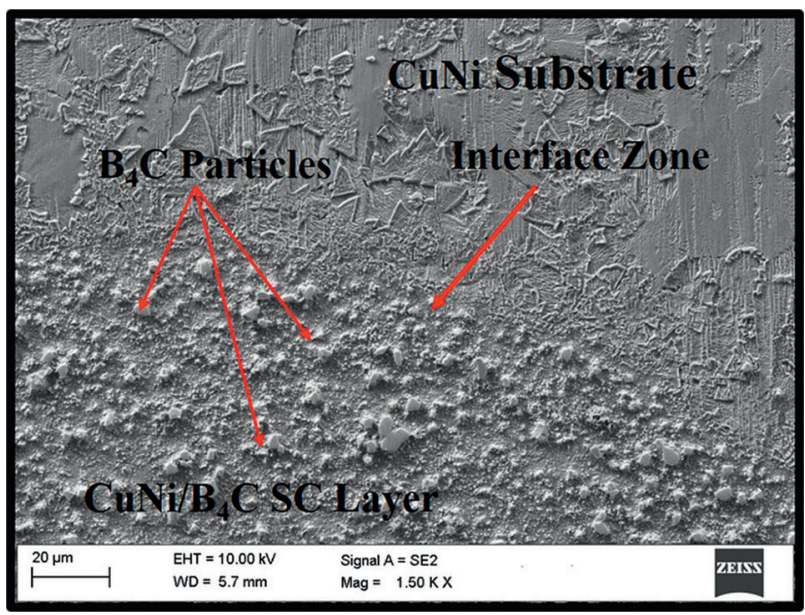

FIGURE 12: FESEM micrograph showing interface zone between $\mathrm{CuNi}$ alloy substrate and $\mathrm{CuNi} / \mathrm{B}_{4} \mathrm{C}$ surface composite layer.

penetration are visible. Figure 13 shows that $\mathrm{B}_{4} \mathrm{C}$ particles appeared at the grain boundary junction (triple point), which confirms the pinning effect along the grain boundaries. The parent material shows a fine grain structure with grain size of $\sim 60 \mu \mathrm{m}$, and it gets significantly reduced to $\sim 5 \mu \mathrm{m}$ at stir zone, which results in good bonding between the particulate and the parent material. When the tool rotates at the stir area, there is a change in metallurgical properties. Figures 14 and 15 show the optical micrographs of the interface between the SZ and TMAZ. Due to the generation of the frictional heat during the FSP, the strain induced plastic deformation of the material which is caused by the tool movement in the soft region, which results in the formation of elongated grain structure in TMAZ zone. The above phenomenon is due to the temperature gradient at different regimes during the FSP $[13,14]$. Plastic deformation of the grains resulted in the formation of highdensity subgrain boundaries. Due to the generation of the frictional heat between the matrix, reinforcement, and stir tool, the adjacent region undergoes extensive changes in grain structure, which is described as TMAZ and HAZ as depicted in Figures 14 and 15. The thickness of each zone varies according to the tool rotational speed.

3.4. Microhardness Survey of FSPed Composites. The microhardness of the FSPed composites is shown in Figure 16. The result of hardness clearly indicates that the fine dispersion of carbide particles resulted in increase of hardness value. When the amount of carbide particles was reinforced at low level, the microhardness of the composite decreased. Thus, an optimum friction stir process at tool rotational speed of $1200 \mathrm{rpm}$ resulted in better microhardness properties. When the tool rotation speed was at maximum level $(1400 \mathrm{rpm})$, a minor increment of hardness was observed which is due to the increased fragmentation of particulates.

3.5. Wear Rate Evaluation. Sliding wear behavior of FSPed samples was investigated using pin-on-disc machine. The

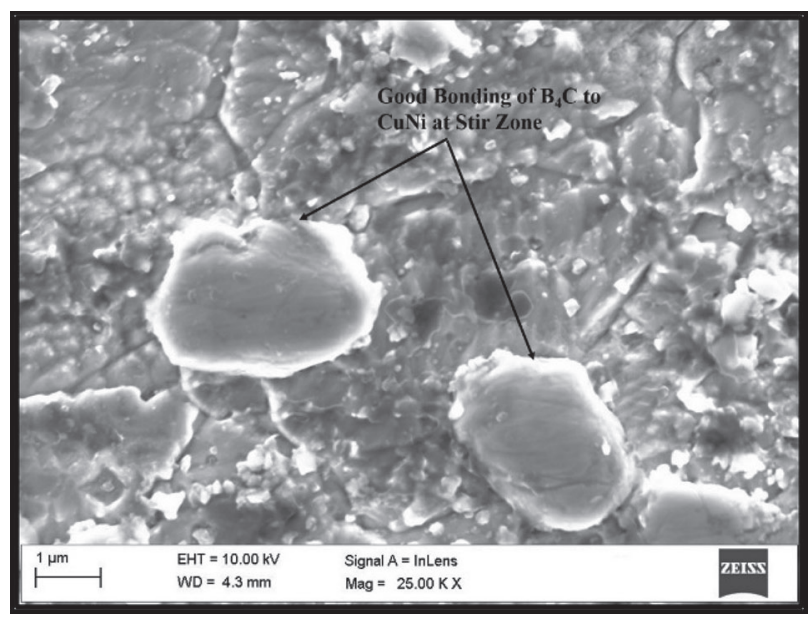

FIGURE 13: FESEM micrograph showing good interfacial bonding between parent metal and carbide particulates in the stir region.

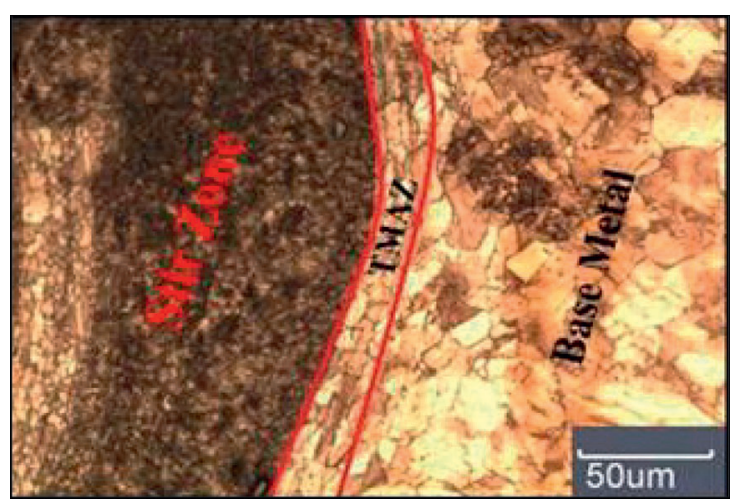

FIgURE 14: Optical micrograph representing stir zone/TMAZ interface.

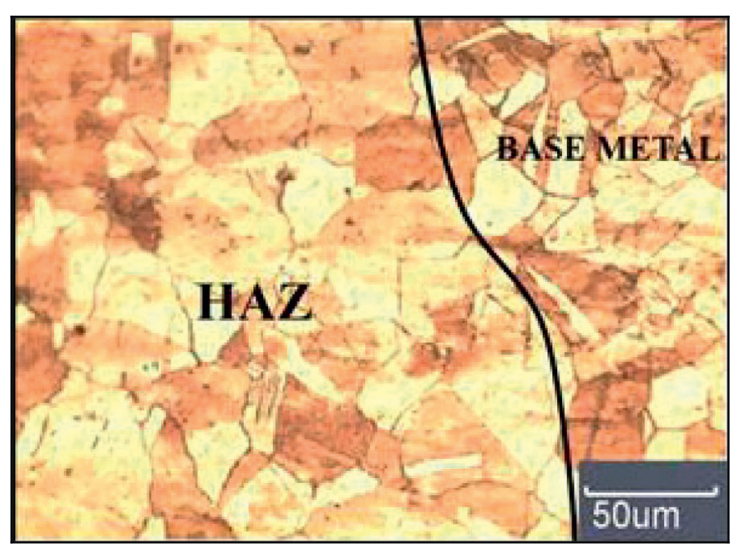

FIgURE 15: Optical micrograph representing HAZ/base metal interface.

pin material selected was FSPed material, and High Chromium High Carbon (HCHC) steel was used as disc. Wear rate of the FSP composite was based on the height change of the specimen prior to and after the test. It was found that the 


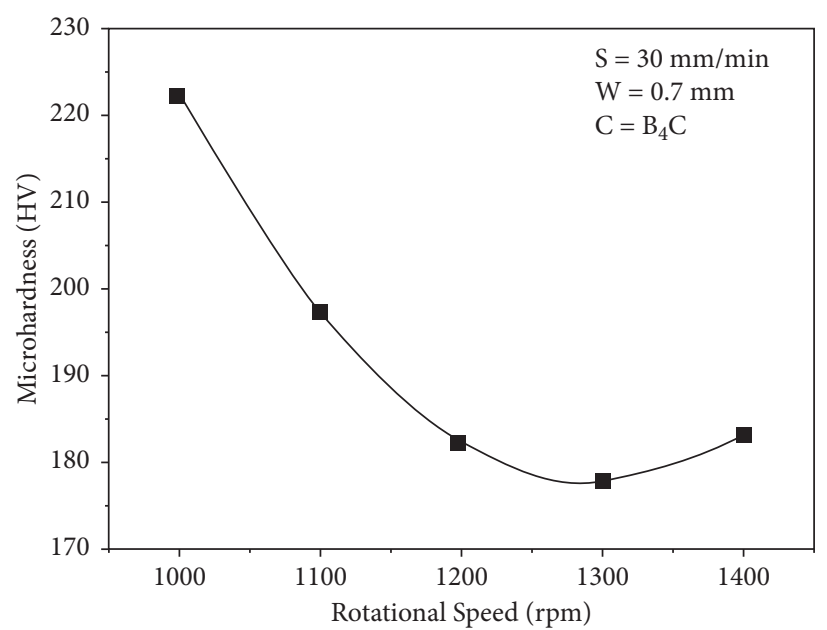

Figure 16: Variations in microhardness as a function of tool rotational speed.

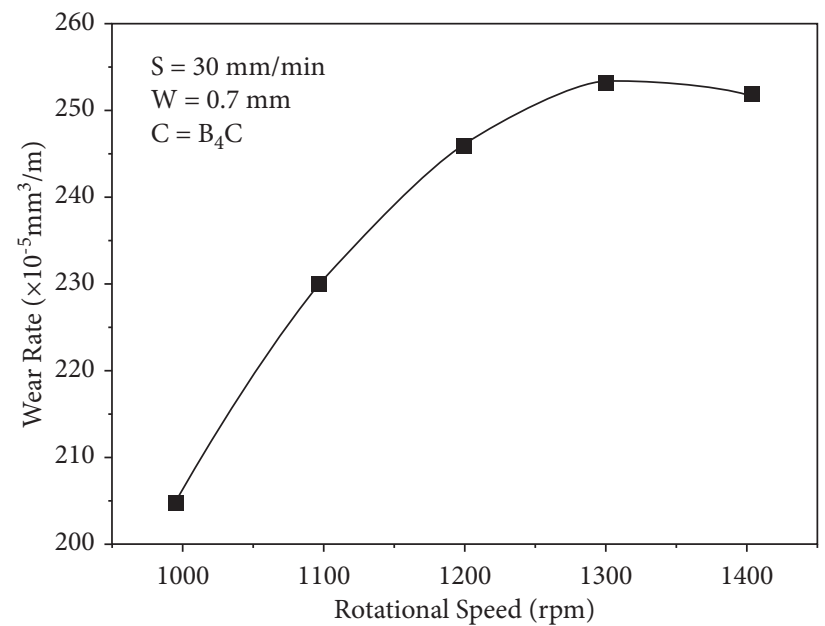

FIgURE 17: Variations in the wear rate of $\mathrm{CuNi} / \mathrm{B}_{4} \mathrm{C}$ surface composite as a function of tool rotational speed.

distribution of hard particle in CuNi matrix material had influenced the trend to increase the wear rate with respect to stir speed. The concentration of hard particle at surface modified region will increase the hardness of the composite, and simultaneously wear rate will be decreased as depicted in Figure 17. However, at higher speed, the particles are partially clustered and induce the matrix material to worn out in the form of abrasion. The pin material gets ploughed during the wear process, and the debris formed were found adhering to the disc. Due to this, three-body wear mechanism started operating, and friction increased over the proposed experimental design. To study the wear mechanism, worn surface morphology was carried out, and the FESEM images are shown in Figures 18(a)-18(c). After wear studies, FSP pin debris were collected during the wear, and the same was observed under FESEM to identify the wear mechanism.

At $1000 \mathrm{rpm}$, the distribution of particle reinforcement was nonuniform when compared to 1200 and $1400 \mathrm{rpm}$. It is clear that the matrix material can hold limited amount of particle at confined zone (over onion ring) and another region is left free. Figure 18(a) shows the matrix after wear studies indication of less wear scars. Figure 18(b) shows slight wear scars along with abrasive grooves while Figure 18(c) shows severe wear over the track of the pin drive. Figure 19 shows that the real morphology of the worn pin was mapped with the support of spectroscopic analysis. The matrix material with particle reinforcement was clearly seen with naked eyes. The dark blue colour shows the distribution of $\mathrm{B} 4 \mathrm{C}$, and mixed red/green shows the presence of matrix material at a tool speed of $1400 \mathrm{rpm}$.

Microscopic images of the wear debris collected for (a) $1000 \mathrm{rpm}$, (b) $1200 \mathrm{rpm}$, and (c) $1400 \mathrm{rpm}$ are shown in Figures 20(a)-20(c). When tool rotational speed increases, interparticle distance also increases, which can be attributed to severe plastic deformation of the base metal. The matrix material removed from the pin is found adhering over the disc surface, and on continued processing, the adhesive 

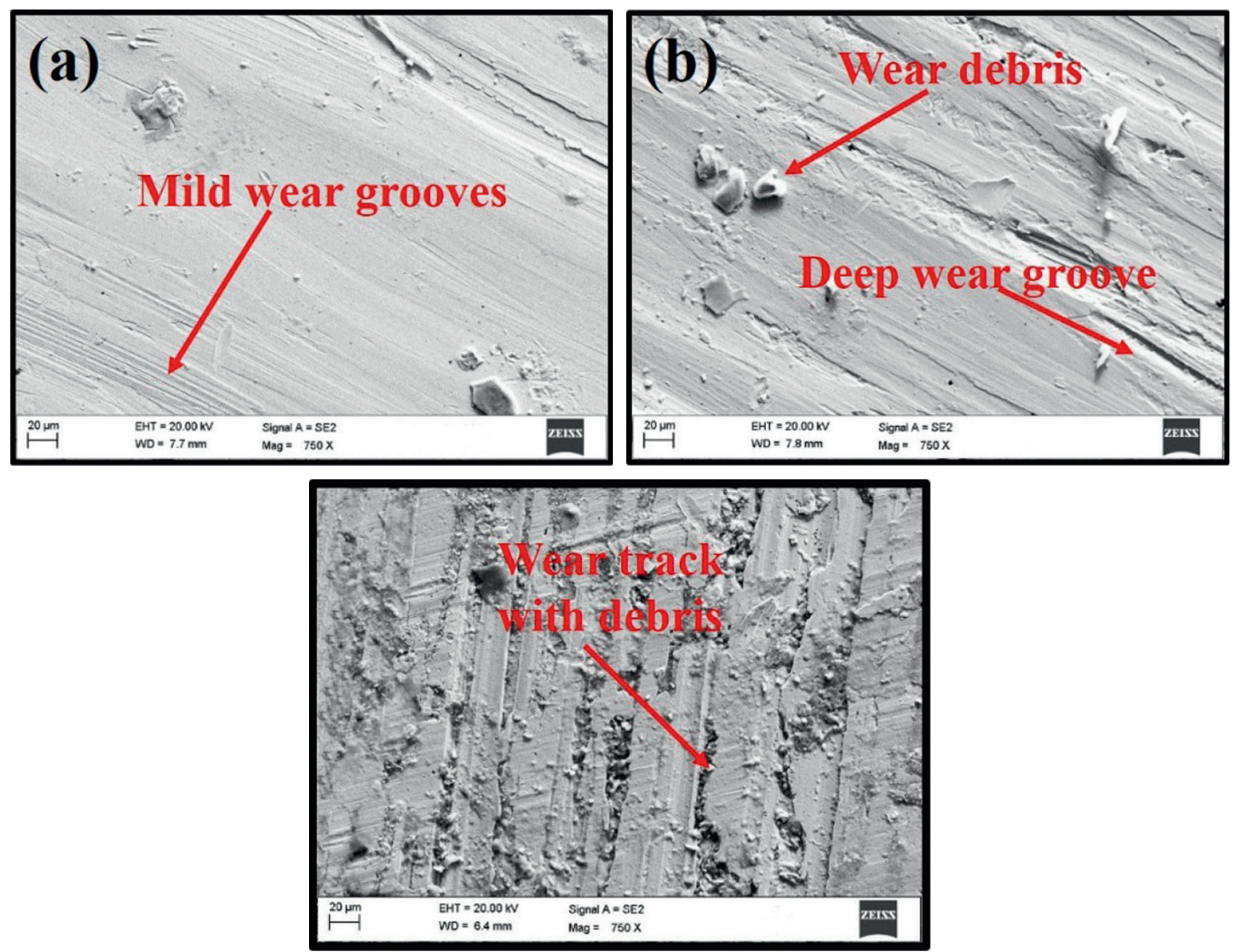

FIGURE 18: FESEM micrograph of worn surface of $\mathrm{CuNi} / \mathrm{B}_{4} \mathrm{C}$ surface composite at tool rotational speed of (a) $1000 \mathrm{rpm}$, (b) $1200 \mathrm{rpm}$, and (c) $1400 \mathrm{rpm}$.

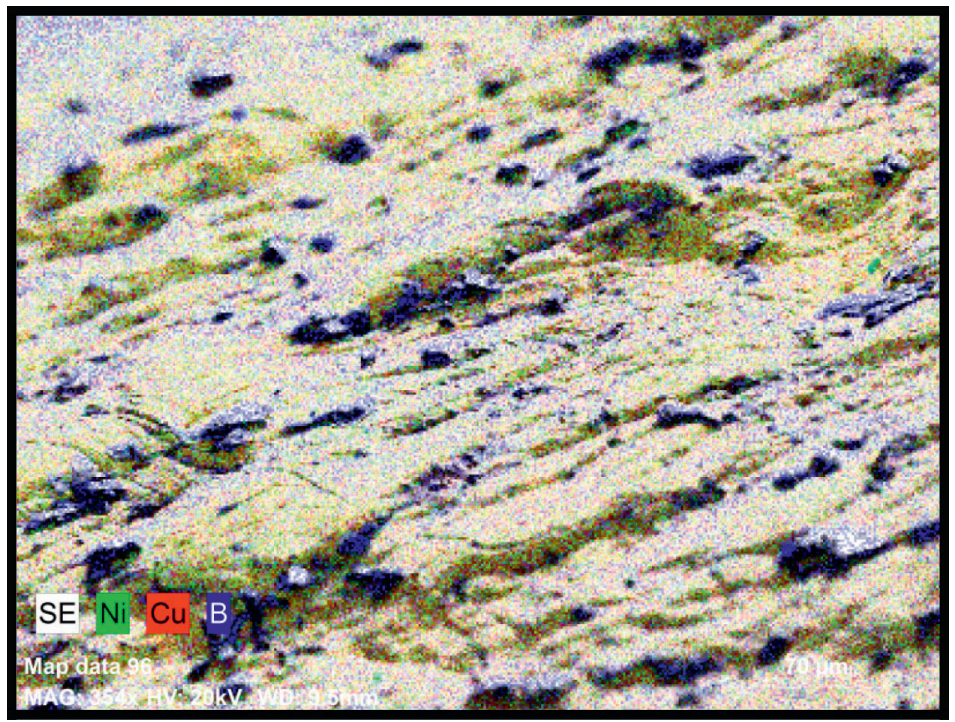

FIGURE 19: Spectroscopic image (mapping) showing the worn out surface of $\mathrm{CuNi} / \mathrm{B}_{4} \mathrm{C}$ surface composite at rotational speed of $1400 \mathrm{rpm}$.

debris were sliced out in the form of flakes. These flakes were $\mathrm{CuNi}$ matrix material in the form of thin film-like structure which has been detached from the surface due to heat generation as a result of friction developed. Adhering debris over the disc has highly influenced the wear-friction relation. Thus, the mechanism involved during the pin on disc sliding wear is of abrasive nature resulting in ploughing of matrix material. 

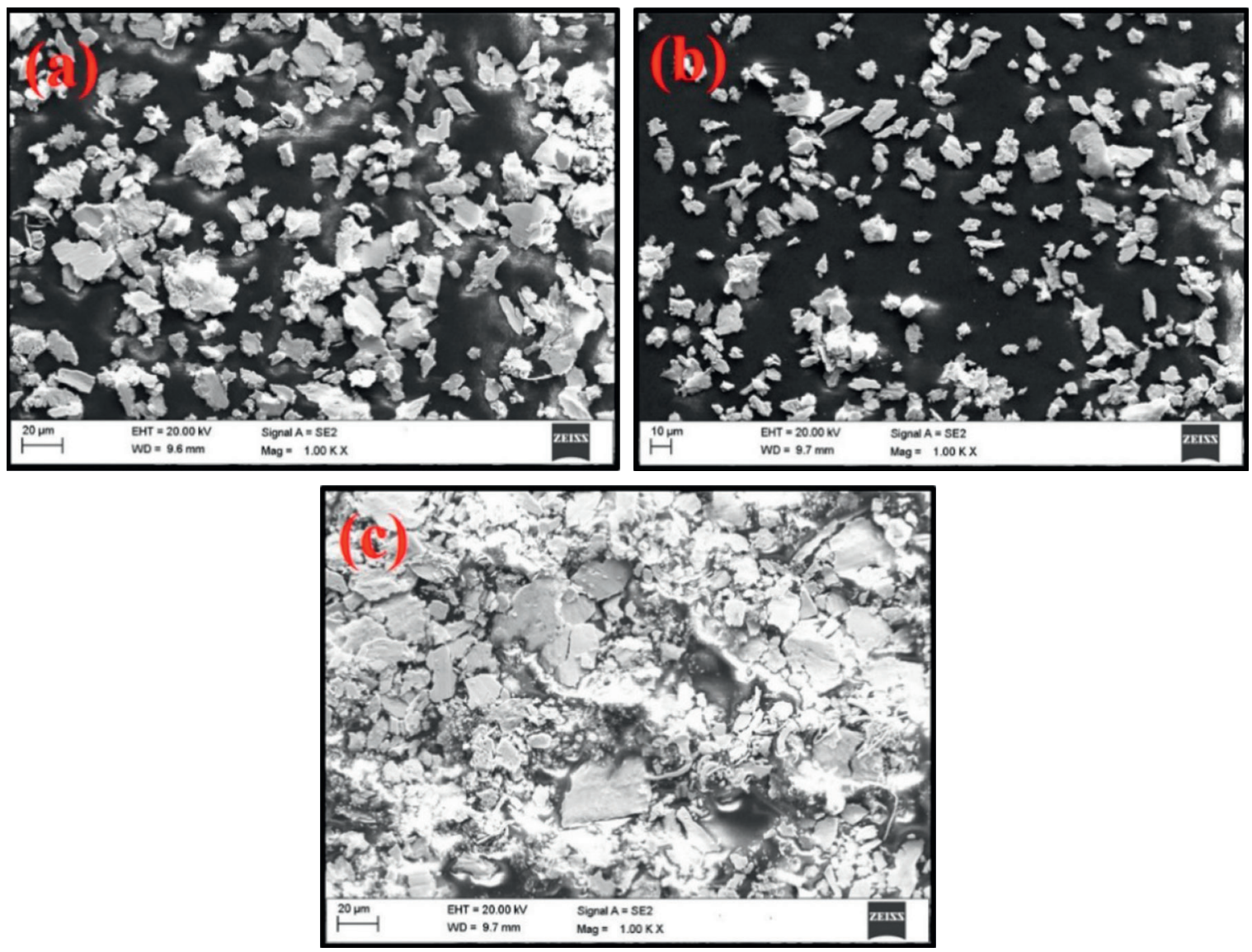

FIgURE 20: FESEM images of the wear debris collected for (a) $1000 \mathrm{rpm}$, (b) $1200 \mathrm{rpm}$, and (c) $1400 \mathrm{rpm}$.

\section{Conclusions}

In the current study, $\mathrm{CuNi} / \mathrm{B}_{4} \mathrm{C}$ surface modified composites were fabricated via FSP, and the influence of tool rotational speed on macrostructure, microstructure, grain size analysis, microhardness, UTS, and wear studies was investigated. The following conclusions can be drawn:

(i) The maximum heat generated at stir zone was found to be $734^{\circ} \mathrm{C}$, and the change in surface of parent metal is a mechanical fusion. Optical and FESEM micrographs, EDS, and XRD pattern clearly reveal the presence and the distribution of $\mathrm{B}_{4} \mathrm{C}$ hard particles over CuNi parent metal.

(ii) With respect to rotational speed, the variation in the FSPed area has been noticed. For a maximum rotation speed of FSP tool (1400 rpm), the mechanical action of the material found is severe, and the stir/ modified area is found to increase $\left(43 \mathrm{~mm}^{2}\right)$. Subsequently, for minimum rotational speed $(1000 \mathrm{rpm})$, the surface area is found to reduce to $36.643 \mathrm{~mm}^{2}$. This is due to the whirling effect and the mechanical strain on the FSP area.

(iii) The microhardness of $\mathrm{CuNi} / \mathrm{B}_{4} \mathrm{C}$ surface composites is decreased when the tool rotational speed increases, which is due to the interparticle distance. As the FSP rotational speed increases, the concentration of hard particle reinforcement is found dispersed over the larges, and the hardness is found to drop from $223 \mathrm{HV}$ to $178 \mathrm{HV}$ gradually.

(iv) The wear rate of $\mathrm{CuNi} / \mathrm{B}_{4} \mathrm{C}$ surface composites decreased with the increase in tool rotational speed. The worn surface morphology shows the presence of tiny size of wear debris at higher tool rotational speed up to optimized value of $1200 \mathrm{rpm}$. There was an increase in size of the wear debris when the tool rotational speed increased to $1400 \mathrm{rpm}$.

\section{Data Availability}

There are no relevant data to be made available.

\section{Conflicts of Interest}

The authors declare that they have no conflicts of interest.

\section{References}

[1] D. C. Agarwal and A. M. Bapat, "Effect of ammonia and sulphide environment on 90/10 and 70/30 Cupronickel Alloy," Journal of Failure Analysis and Prevention, vol. 9, no. 5, pp. 444-460, 2009.

[2] D. C. Agarwal, "Effect of ammoniacal seawater on material properties of copper nickel alloys," Br.Corros. J, vol. 37, no. 2, 2002. 
[3] R. V. Vignesh, R. Padmanaban, M. Govindaraju, and G. S. Priyadharshini, "Investigations on the corrosion behaviour and biocompatibility of magnesium alloy surface composites AZ91D-ZrO2 fabricated by friction stir processing," Transactions of the IMF, vol. 97, no. 5, pp. 261-270, Article ID 085401, 2019.

[4] S. Sahraeinejad, H. Izadi, M. Haghshenas, and A. P. Gerlich, "Fabrication of metal matrix composites by friction stir processing with different Particles and processing parameters," Materials Science and Engineering A, vol. 626, pp. 505-513, 2015.

[5] T. Satish Kumar, S. Shalini, and K. Krishna Kumar, "Effect of friction stir processing and hybrid reinforcement on wear behaviour of AA6082 alloy composite," Materials Research Express, vol. 7, no. 2, pp. 195-204, Article ID 026507, 2020.

[6] G. S. Priyadharshini, R. Subramanian, N. Murugan, and R. Sathiskumar, "Surface modification and characterization of zirconium carbide particulate reinforced C70600 CuNi composite fabricated via friction stir processing," Journal of Mechanical Science and Technology, vol. 31, no. 8, pp. 37553760, 2017.

[7] E. R. I. Mahmoud, M. Takahashi, T. Shibayanagi, and K. Ikeuchi, "Effect of friction stir processing tool probe on fabrication of SiC particle reinforced composite on aluminium surface," Science and Technology of Welding \& Joining, vol. 14, no. 5, pp. 413-425, 2009.

[8] R. Palanivel, I. Dinaharan, R. F. Laubscher, and J. P. Davim, "Influence of boron nitride nanoparticles on microstructure and wear behavior of AA6082/TiB 2 hybrid aluminum composites synthesized by friction stir processing," Materials \& Design, vol. 106, pp. 195-204, 2016.

[9] H. S. Chen, Y. Zhang, H. H. Nie, J. F. Wang, and W. X. Wang, "The microstructure and mechanical properties of the $\mathrm{B} 4 \mathrm{C} / \mathrm{Cu}$ matrix composite fabricated by SPS-HR," Mater.Sci \& Tech, vol. 34, pp. 1460-1467, 2018.

[10] R. Sathiskumar, N. Murugan, I. Dinaharan, and S. J. Vijay, "Prediction of mechanical and wear properties of copper surface composites fabricated using friction stir processing," Materials \& Design, vol. 55, pp. 224-234, 2014.

[11] H. Woo, H. Choo, D. W. Brown, and Z. Feng, "Influence of the tool pin and shoulder on microstructure and natural aging kinetics in a friction-stir-processed 6061- T6 aluminium alloy," Metallurgical and Materials Transactions A, vol. 38, pp. A69-A76, 2014.

[12] C. Kalangi, V. Bolleddu, and H. L. Allasi, "Tribological characteristics of Carbon nanotubes-reinforced plasmasprayed Al2O3-TiO2 ceramic coatings," Advances in Materials Science and Engineering, vol. 2021, Article ID 8094640, 12 pages, 2021.

[13] A. Haiter Lenin, S. C. Vettivel, T. Raja, L. Belay, and S. Christopher Ezhil Singh, "A statistical prediction on wear and friction behavior of $\mathrm{ZrC}$ nano particles reinforced with Al-Si composites using full factorial design," Surfaces and Interfaces, vol. 10, pp. 149-161, 2018.

[14] G. Robert Singh, C. E. Singh, M. Sivapragash, L. Anselm, R. S. Kumar, and A. Haiter Lenin, "Tensile and compression behaviour, microstructural characterization on Mg-3Zn-3Sn$0.7 \mathrm{Mn}$ alloy reinforced with $\mathrm{SiCp}$ prepared through powder metallurgy method," Materials Research Express, vol. 7, no. 10, Article ID 106512, 2020. 